\title{
Lysophosphatidic Acid: A Key Player in Obesity
}

\author{
Saima $\mathrm{SM}^{1}$ Hina $\mathrm{FB}^{2 *}$ and Zuhailb $\mathrm{FB}^{3}$ \\ ${ }^{1}$ Department of Biotechnology, India \\ ${ }^{2}$ Division of Animal Biotechnology, India \\ ${ }^{3}$ Department of Food Sciences, New Zealand
}

ISSN: 2578-0263

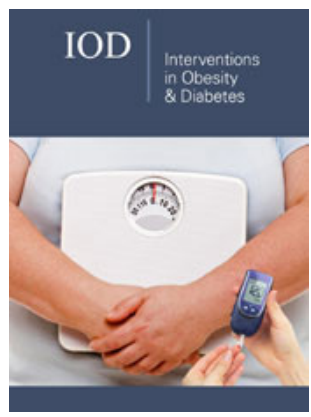

*Corresponding author: Hina FB, Division of Animal Biotechnology, India

Submission: 眥 February 19, 2019

Published: 䟧April 25,2019

Volume 2 - Issue 5

How to cite this article: Saima S, Hina F Zuhaib F. Lysophosphatidic Acid: A Key Player in Obesity. Interventions Obes Diabetes. 2(5). IOD.000547.2019. DOI: 10.31031/IOD.2019.02.000547

Copyright@ Hina FB, This article is distributed under the terms of the Creative Commons Attribution 4.0 International License, which permits unrestricted use and redistribution provided that the original author and source are credited.

\begin{abstract}
In an obese individual, elevated levels of no esterified fatty acids, glycerol, hormones, cytokines, proinflammatory substances, and other substances have been observed. Adipokine, autotoxin (ATX) released by adipocytes exerts a paracrine control over adipogenesis via LPA production which in turn aggravates obesity and insulin resistance in affected individuals. Obesity and its associated disorders (glucose homeostasis and cardiovascular disease like atherosclerosis) show an upregulated expression of ATX- LPA, which makes it a druggable target to treat obesity. In this review we have highlighted the role of lysolipid, LPA and its receptors in obesity and associated anomalies.
\end{abstract}

\section{LPA Receptor Expression in Obesity}

LPA receptor signaling has been implicated in severe non communicable diseases including cardiovascular disease, cancer, bone development and disease, fibrosis, reproductive disorders, schizophrenia and obesity [1-3]. It has also been implicated in the regulation of glucose homeostasis and obesity-related metabolic disease in mice and humans [4]. LPA activates multiple rhodopsin like G protein coupled receptors (LPA1-6) [5], which are expressed in heart and adipose tissue at distinct levels with a significant increase in levels of LPA 4, 5 and 6 in the heart of obese mice, although undetectable levels of LPA3 have been observed in adipocytes of mice and subcutaneous adipose tissue in humans [5,6]. Some other studies have reported LPA1, LPA2, LPA3 and LPA6 expression in primary rat hepatocytes with the highest expression of the LPA3 receptor subtype [7]. LPA4, LPA5, and/or LPA6 are significantly increased in myocardial tissue and cells from HFHS-fed mice and humans with pre obesity or obesity. Recently it has been suggested that plasma LPA positively correlates well with body mass index (BMI), an indicator of nutritional imbalance [8]. Evidences have proven that in human atrial tissue, LPA4 and LPA5 mRNA levels correlate well with BMI and waist circumference besides LPA3 stimulation is involved in attenuation of insulin-dependent signaling in hepatocytes in mice with obesity. Although LPA3 is not significantly expressed in mice and human heart but it is the crucial receptor subtype involved in the inhibitory effect of LPA on insulin signaling associated with obesity [9]. LPA1 is abundantly expressed in kidney cortex, playing a vital role in glomerular injury in diabetic mice [10]. Even if very little is known about the regulation of LPA receptor expression in obesity and heart disease, however, specific receptor targeting of the LPA signaling network thus may provide novel avenues for further therapeutic development in obesity and associated disorders.

\section{ATX-LPA Signaling in Obesity}

Studies have suggested that the consumption of a fat-rich diet in mice models leads to increased circulating levels of LPA suggesting diet induced upregulation of LPA. However, the diet induced upregulation of LPA is a consequence of altered regulation of precursor lipids for LPA production rather than from absorbance of preformed dietary LPA from the lipid rich diet (obesogenic diet) [11]. A diet rich in animal fats leads to deposition of fats in adipose tissue, which secretes autotoxin (ATX) and biologically active LPA $[12,13]$ in the extracellular environment of obese, insulin-resistant individuals and mice. During development of obesity, expansion of white adipose tissue signifies the hallmark of obesity which involves the proliferation and differentiation of adipose precursors. Increased level of LPA induces adipocyte proliferation in white adipocytes via LPA1/MAPK (Ras-mitogen activated protein 
kinase) pathway, and inhibits adipogenesis by down-regulation of the pro-ad pyogenic transcription factor PPARY2 via LPA1/Rho kinase pathway [12] and delayed activation of the WNT-signaling pathway in preadipocytes, thereby altering adipose tissue biology [13-15].

Studies point towards the key role of LPA in obesity as it controls adiposity as well as glucose homeostasis including insulin resistance in obese individuals. Increased insulin secretion being a common consequence of obesity, accompanied by insulin resistance, is considered as a major cause of fatal disorders including type 2 diabetes (T2DM), endothelial dysfunction, hypertension, dyslipidemia and cardiovascular diseases [16]. LPA signaling pathway plays a prominent role in obesity related disorders in vivo and in vitro. Yea et al. [17] for the first-time reported involvement of LPA signaling in regulation of glucose metabolism in skeletal muscle cells and adipose tissues. Physiologically insulin-mediated PI3K activation via phosphorylation of GSK-3 $\beta$ results in an elevated hepatic glycogen, however LPA stimulation interrupts insulin-induced Gck expression, PI3K activation and glycogen synthesis in primary rat hepatocytes via the LPA3 receptor subtype $[7,17]$. Further studies have shown that LPAR antagonist improves the glucose and insulin tolerance in obese mice which demonstrates the inhibitory effect of LPA on glucose homeostasis likely through inhibition of insulin secretion during obesity [4]. Moreover, proinflammatory factors have been observed to increase systematically in obesity and contribute to the development and/ or exacerbation of insulin resistance. It is believed that ATXLPA signaling promotes insulin resistance via local and systemic inflammation as well $[6,18]$.

An elevated LPA level reported in heart suggests its impact in cardiovascular disease, particularly atherosclerosis, associated with obesity, insulin resistance, and diabetes. LPA present in atherosclerotic plaque promotes atherosclerosis development, inflammation, and thrombosis by platelet aggregation $[9,19]$. LPA receptor signaling under diabetic conditions augments TGF- $\beta$ expression via GSK3- $\beta$ phosphorylation and SREBP1 activation, subsequently contributing to the development of diabetic nephropathy [10]. Taken together, these studies suggest a potential link between the ATX-LPA signaling axis and Obesity/related disorders [20-22].

\section{Concluding Remarks}

Obesity increases the risk of several fatal and non-fatal diseases and contributes to functional disabilities and even death. Both exogenous and endogenous LPA display a considerable role in the signaling pathways resulting in metabolic and inflammatory disorders including obesity. It alters the expression of hormones, growth factors, inflammatory, cytokines and adipokines, which consequently promote cancer cell survival, metastasis and angiogenesis. Since LPA plays a significant role in cancer progression, it may prove a potential link between obesity and related cancer progression in obese individuals as well. Pharmacological blockade of relevant LPA receptor subtypes could be considered as a much more effective therapeutic strategy for the treatment of obesity \& related pathological conditions.

\section{Acknowledgement}

The work was supported by the Department of Science and Technology, Government of India, under the DST-INSPIRE Faculty award 2013 from (Ref No: DST/INSPIRE/04/2013/000997) and Science and Engineering Research Board (SERB-India) (ECR/2016/000272/LS).

\section{References}

1. Lin ME, Herr DR, Chun J (2010) Lysophosphatidic acid (LPA) receptors: signaling properties and disease relevance. Prostaglandins Other Lipid Mediat 91(3-4): 130-138.

2. Choi JW, Herr DR, Noguchi K, Yung YC, Lee CW, et al. (2010) LPA receptors: subtypes and biological actions. Annu Rev Pharmacol Toxicol 50: 157-186.

3. Willier S, Butt E, Grunewald TG (2013) Lysophosphatidic acid (LPA) signaling in cell migration and cancer invasion: a focused review and analysis of LPA receptor gene expression on the basis of more than 1700 cancer microarrays. Biol Cell 105(8): 317-333.

4. Rancoule C, Attané C, Grès S, Fournel A, Dusaulcy R, et al. (2013) Lysophosphatidic acid impairs glucose homeostasis and inhibits insulin secretion in high-fat diet obese mice. Diabetologia 56(6): 1394-1402.

5. Bandoh K, Aoki J, Taira A, Tsujimoto M, Arai H, et al. (2000) Lysophosphatidic acid (LPA) receptors of the EDG family are differentially activated by LPA species. FEBS Lett 478(1-2): 159-165.

6. Rancoule C, Dusaulcy R, Treguer K, Gres S, Attane C, et al. (2014) Involvement of autotaxin/lysophosphatidic acid signaling in obesity and impaired glucose homeostasis. Biochimie 96: 140-143.

7. Fayyaz S, Japtok L, Schumacher F, Wigger D, Schulz TJ, et al. (2017) Lysophosphatidic acid inhibits insulin signaling in primary rat hepatocytes via the LPA3 receptor subtype and is increased in obesity. Cell Physiol Biochem 43(2): 445-456.

8. Michalczyk A, Budkowska M, Dolegowska B, Chlubek D, Safranow K (2017) Lysophosphatidic acid plasma concentrations in healthy subjects: Circadian rhythm and associations with demographic, anthropometric and biochemical parameters. Lipids Health Dis 16(1): 140.

9. Brown A, Hossain I, Perez LJ, Nzirorera C, Tozer K, et al. (2017) Lysophosphatidic acid receptor mRNA levels in heart and white adipose tissue are associated with obesity in mice and humans. PLoS One 12(12): e0189402.

10. Li HY, Oh YS, Choi JW, Jung JY, Jun HS (2017) Blocking lysophosphatidic acid receptor 1 signaling inhibits diabetic nephropathy in $\mathrm{Db} / \mathrm{Db}$ mice. Kidney Int 91(6): 1362-1373.

11. Hough GNM, Buga GM, Su F, Wagner AC, Meriwether D, et al. (2013) Transgenic $6 \mathrm{~F}$ tomatoes act on the small intestine to prevent systemic inflammation and dyslipidemia caused by western diet and intestinally derived lysophosphatidic acid. J Lipid Res 54(12): 3403-3418.

12. Souza KD, Kane DA, Touaibia M, Kershaw EE, Pulinilkunnil T, et al. (2017) Autotaxin is regulated by glucose and insulin in adipocytes. Endocrinology 158(4): 791-803.

13. Ferry G, Tellier E, Try A, Gres S, Naime I, et al. (2003) Autotaxin is released from adipocytes, catalyzes lysophosphatidic acid synthesis, and activates preadipocyte proliferation. Up-regulated expression with adipocyte differentiation and obesity. J Biol Chem 278(20): 1816218169.

14. Simon MF, Daviaud D, Pradere JP, Gres S, Guigne C, et al. (2005) Lysophosphatidic acid inhibits adipocyte differentiation via lysophosphatidic acid 1 receptor-dependent down-regulation of peroxisome proliferator-activated receptor gamma 2. J Biol Chem 280(15): 14656-14662.

15. Lee MJ, Wu Y, Fried SK (2010) Adipose tissue remodeling in pathophysiology of obesity. Curr Opin Clin Nutr Metab Care 13(4): 371376. 
16. Goblan ASA, Alfi MA, Khan MZ (2014) Mechanism linking diabetes mellitus and obesity. Diabetes Metab Syndr Obes 7: 587-591.

17. Yea K, Kim J, Lim S, Park HS, Park KS, et al. (2008) Lysophosphatidic acid regulates blood glucose by stimulating myotube and adipocyte glucose uptake. J Mol Med (Berl) 86(2): 211-220.

18. Souza KD, Paramel GV, Kienesberger PC (2018) Lysophosphatidic acid signaling in obesity and insulin resistance. Nutrients 10(4): E399.

19. Schober A, Siess W (2012) Lysophosphatidic acid in atherosclerotic diseases. Br J Pharmacol 167(3): 465-482.
20. Boucher J, Quilliot D, Praderes JP, Simon MF, Gres S, et al. (2005) Potential involvement of adipocyte insulin resistance in obesity-associated upregulation of adipocyte lysophospholipase D/autotaxin expression. Diabetologia 48(3): 569-577.

21. Blache JSS (2006) Secretion and role of autotaxin and lysophosphatidic acid in adipose tissue. J Soc Biol 200(1): 77-81.

22. Fang X, Gaudette D, Furui T, Mao M, Estrella V, et al. (2000) Lysophospholipid growth factors in the initiation, progression, metastases, and management of ovarian cancer. Ann N Y Acad Sci 905: 188-208. 